\title{
Cardiovascular risk assessment in rheumatoid arthritis with nodulosis: approach to primary prevention
}

\author{
Dinu Valentin Balanescu' ${ }^{1}$ Cristina Ileana losif², Andra Rodica Balanescu', \\ Ruxandra Ionescu' ${ }^{1}$, DenisaPredeteanu' ${ }^{1}$ \\ ${ }^{1}$ Department of Internal Medicine and Rheumatology, "Sf. Maria" Clinical Hospital, Bucharest, Romania \\ 2Department of Pathology, "Sf. Maria"Clinical Hospital, Bucharest, Romania
}

\begin{abstract}
Cardiovascular risk assessment in patients with rheumatoid arthritis (RA) is challenging. Not all risk calculators adjust for RA status, yielding discording results. A 56-year-old woman with RA presented for bilateral pain and swelling in the metacarpophalangeal (MCP) and proximal interphalangeal (PIP) joints. She was diagnosed with RA 10 years ago, currently treated with methotrexate (MTX), sulfasalazine, and hydroxychloroquine. She has a history of type 2 diabetes mellitus, a total abdominal hysterectomy with bilateral salpingo-oophorectomy for an epidermoid carcinoma of the cervix, and surgical excision of a pulmonary rheumatoid nodule. Multiple subcutaneous nodules are seen bilaterally on the MCP and PIP joints. MTX may be associated with nodulosis in RA patients, which in turn is related to a further increase in cardiovascular risk compared to RA alone. MTX was discontinued. Abatacept was the biologic of choice, due to recent evidence suggesting superior efficacy in decreasing cardiovascular risk compared to anti-TNF therapies, especially in patients with diabetes and with positive rheumatoid factor. Initiating high-dose statin and abatacept may be a useful primary prevention strategy in complex RA patients that require biologic therapy..
\end{abstract}

Keywords: abatacept; cardiovascular risk assessment; methotrexate; nodulosis; rheumatoid arthritis

\section{INTRODUCTION}

The excess cardiovascular risk in rheumatoid arthritis (RA) patients is an important cause of morbidity and mortality (1). This added risk is brought on by the complex mechanisms of RA, which complement the action of traditional cardiovascular risk factors (2). Although RA has been well described as an independent cardiovascular risk factor (3), societal guidelines differ regarding the approach to cardiovascular primary prevention in RA patients. Adding to this challenge is the lack of validation of many cardiovascular risk calculators specifically for the RA population, which are known to underestimate the risk in these patients $(4,5)$. We present an example of managing cardiovascular primary prevention in a middle-aged woman with RA, nodulosis, and both traditional and non-traditional risk factors.

\section{CASE REPORT}

A 56-year-old woman with RA presented for bilateral pain and swelling in the metacarpophalangeal (MCP) joints. She was diagnosed with RA 10 years ago, when she presented with swollen knees and nodules on the MCP joints. Her current RA treatment consists of triple therapy with methotrexate (MTX) $10 \mathrm{mg} /$ week, sulfasalazine $2 \mathrm{~g} /$ day, and hydroxychloroquine $400 \mathrm{mg} /$ day. She has a history of type 2 diabetes mellitus (diagnosed at age 20, currently on $40 \mathrm{UI}$ insulin daily) and a total abdominal hysterectomy with bilateral salpingo-oophorectomy for an epidermoid carcinoma of the cervix (8 years ago). During one of her routine follow-up computed tomography exams in 2013, a pulmonary nodule was described, which was eventually removed surgically. The pathology exam confirmed it was a rheumatoid 
nodule (Fig. 1). At the current presentation, rheumatoid nodules on the MCP and proximal interphalangeal joints (PIP) are seen (Fig. 2). Labs show a normal lipid profile, an ESR of $14 \mathrm{~mm} / \mathrm{h}$, a CRP of $20.83 \mathrm{mg} / \mathrm{L}$, and a rheumatoid factor (RF) of $325 \mathrm{UI} /$ $\mathrm{mL}$. A chest X-ray revealed mild emphysema, with no nodules. An ultrasound of her hands revealed bilateral grade II tenosynovitis and rheumatoid nodules on the MCP and PIP joints with an active Doppler signal and joint erosion.

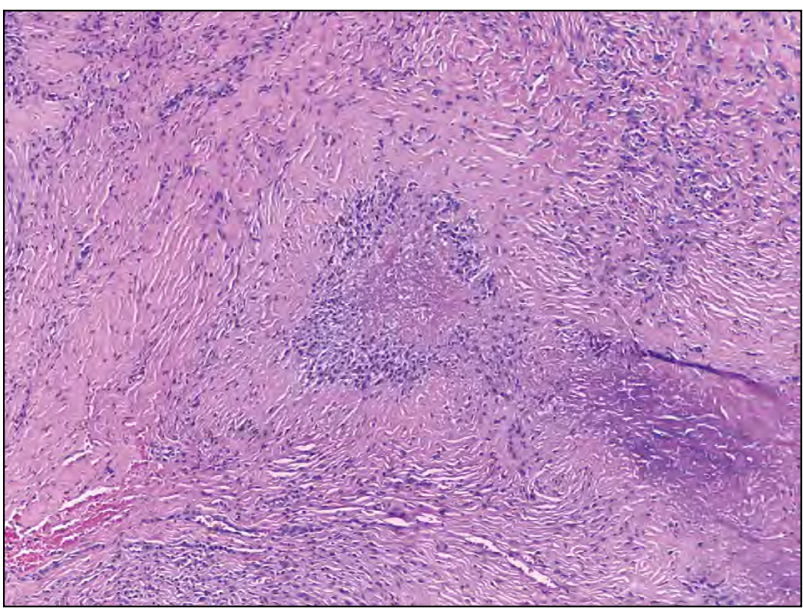

FIGURE 1. Surgically-removed pulmonary rheumatoid nodule

Hematoxylin-eosin-stained sample of a surgically-removed rheumatoid nodule (20X)

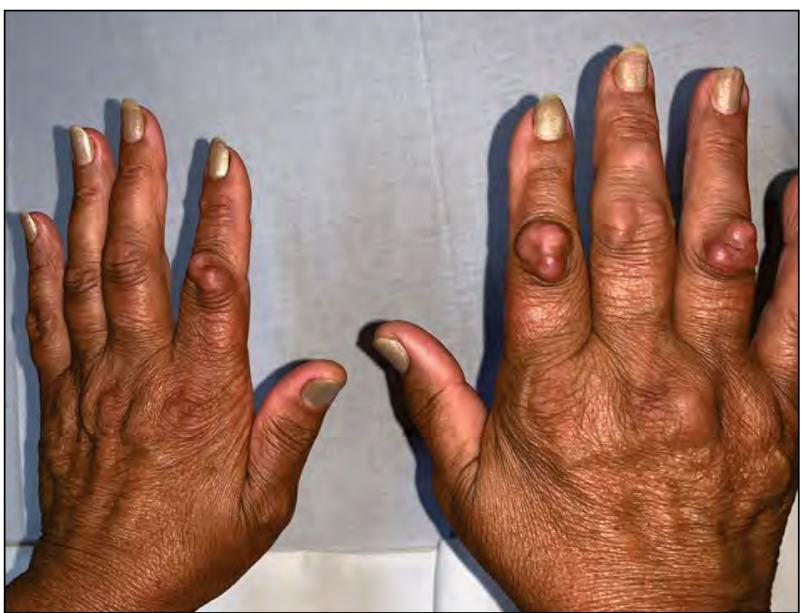

FIGURE 2. Rheumatoid nodules on the metacarpophalangeal and proximal interphalangeal joints

Two management issues were raised: decreasing RA activity and assessing cardiovascular risk. Due to her lack of response to triple therapy with non-biologic disease modifying anti-rheumatic drugs (DMARDs), biologic therapy was proposed. An additional argument for MTX discontinuation is its effect on the appearance and progression of nodulosis. Generally, tumor necrosis factor (TNF) inhibitors are the first choice for biologic therapies in RA, with a similar efficacy among drugs of this class (6). However, the cardiovascular risk must also be taken into account in a patient with both traditional risk factors (diabetes, smoking) and non-traditional risk factors (RA, high RF values, nodulosis). Abatacept was the biologic drug of choice, as it has been recently shown to be superior to TNF inhibitors for decreasing cardiovascular risk, especially in diabetic patients with rheumatoid autoimmunity (7). Using the ACC/AHA guidelines, the patient qualified for high-dose statin therapy despite a normal lipid profile, and atorvastatin $40 \mathrm{mg}$ daily was initiated. The patient was referred to her oncologist for pre-abatacept assessment.

\section{DISCUSSION}

Rheumatoid nodules are a common manifestation of RA occurring subcutaneously (on pressure points) or within internal organs of the body. Subcutaneous nodules can be found in $30-40 \%$ of RA patients (8), but they can infrequently occur in patients with systemic lupus erythematosus, ankylosing spondylitis, granuloma annulare, chronic active hepatitis, and in healthy children and adults (9). Rheumatoid nodules are firm, nontender, mobile subcutaneous nodules varying in size between $2 \mathrm{~mm}$ to $5 \mathrm{~cm}$ (9). Although not usually of cosmetic concern or symptomatic, the nodules can interfere with function and cause compressive neuropathies, or they can ulcerate and serve as a site for local or distant infections. The impact of evolving treatment strategies on the incidence of rheumatoid nodules is uncertain. It has been reported that nodule-formers have positive rheumatoid factor, antibodies to citrullinated proteins (ACPA), and antiphospholipid antibodies (1012). Patients with rheumatoid nodules generally have more severe, destructive, and complicated RA disease forms (13). Subcutaneous rheumatoid nodules are associated with an increased risk for cardiovascular disease as well as cardiovascular, respiratory, and all-cause mortality $(14,15)$. There is a need for careful assessment and modification of cardiovascular risk factors in these patients.

Pulmonary nodules have traditionally been considered a rare occurrence in RA patients, but the prevalence depends on the detection method used $(0.4 \%$ with plain film radiographs and $32 \%$ with open lung biopsies) $(16,17)$. Nodules can be found in subpleural areas or in association with interlobu- 
lar septa. They can be associated with pleural effusion, pneumothorax, pyopneumothorax, bronchopleural fistula, and hemoptysis. Other rare locations of rheumatic nodules include the heart (e.g., pericardium, myocardium, valvular structures) and the central nervous system.

Accelerated nodulosis is a poorly understood proinflammatory effect associated with MTX treatment where patients experience an increase in nodule size and number (otherwise similar in morphology and clinical manifestations to usual RA nodules), even when synovial inflammation is suppressed (18). The nodules typically develop primarily over the fingers, hands, or wrists, but other locations have also been described (e.g., elbows, scalp, Achilles tendon, larynx, and lungs) $(19,20)$. The onset of MTX-induced accelerated nodulosis can occur within a very wide timeframe from MTX therapy initiation (one month - eight years). This complication may be caused by the activation of adenosine A1 receptors by MTX, leading to the formation of multinucleated giant cells (21). MTX discontinuation and a change to alternative treatment regimens can be taken into consideration, as approximately $70 \%$ of cases of accelerated nodulosis resolve with stopping MTX (19). No specific treatment has proven to be beneficial for MTX-associated nodulosis, although there are reports suggesting that rituximab and tocilizumab could potentially play a beneficial role $(22,23)$. Nodulosis has been reported in RA patients in association with leflunomide, azathioprine (9), and TNF inhibitors (24). Smoking may be a risk factor for developing rheumatoid nodules, but also for vasculitis and other severe manifestations of RA (25-27).

In this complex case, a histopathologic exam of the pulmonary nodule was necessary to differentiate between metastasis from her prior uterine cancer and a rheumatoid nodule.

Cardiovascular disease remains the most common cause of death in RA (28). Large meta-analyses identified an increase of $48 \%$ in cardiovascular events and a $50 \%$ higher incidence of mortality from cardiovascular causes in RA patients compared to the general population $(29,30)$. This risk seems to be added more by the complementary action of traditional risk factors and RA, rather than from RA itself. Prospective studies that adjusted for RA status identified traditional risk factors (i.e., smoking, hypertension, and diabetes) to be more predictive of markers of cardiovascular disease (e.g., carotid me- dia intima thickness, endothelial function, microvascular function, coronary artery calcium scores) (31, 32). It is unclear how well represented traditional risk factors are in RA patients compared to the general population (33). However, among traditional risk factors, smoking has been well associated with the progression of both cardiovascular disease and RA (34). Current evidence established a pivotal role of inflammation in the development of cardiovascular disease, an element which differentiates RA patients from the general population. Higher disease activity, as assessed by biologic (e.g., ESR, CRP, $\mathrm{RF}$ ) or clinical (e.g., DAS28) markers, have been associated with worse cardiovascular function and outcomes (35-40). Controlling RA appears to "normalize" the risk, which highlights the importance of proper RA management in cardiovascular prevention (41).

Decreasing cardiovascular risk in RA patients may be approached by 3 strategies, as recently proposed by Chodara et al. (28): decreasing RA activity, assessing cardiovascular risk using risk calculators, and controlling traditional cardiovascular risk factors. These strategies also form the basis of the "EULAR recommendations for cardiovascular disease risk management in patients with RA and other forms of inflammatory joint disorders" (42).

MTX is the most used non-biologic DMARD in RA. MTX is known to decrease cardiovascular risk through several mechanisms, including decreasing pro-inflammatory cytokines and activating the adenosine $\mathrm{A} 2{ }_{\mathrm{A}}$ receptor, resulting in an anti-atherosclerotic effect (43). Decreased cardiovascular risk is observed despite the hyperhomocysteinemia associated with this agent. TNF inhibitors have been shown to decrease cardiovascular risk compared to non-biologic DMARDs (44). According to a large meta-analysis, TNF inhibitors appear to decrease the risk for cardiovascular events by $30 \%$ in RA patients (RR 0.7, CI 0.54-0.9) (45) and may also improve outcomes following a cardiovascular event (46). This effect is independent of managing traditional risk factors, which suggests that it is the result of decreasing systemic inflammation (44). Although this benefit is similar among TNF inhibitors, recent data suggests the superiority of abatacept for improving cardiovascular outcomes, especially in the setting of diabetes (7). Further randomized clinical trials are needed in order to definitively prove the cardiovascular benefits of biologic therapy in RA. In our patient, we considered abatacept to be of most 
benefit for several reasons: the need for biologic therapy to decrease disease activity, to avoid anti-TNF therapy which may contribute to nodulosis, and to decrease cardiovascular risk (particularly in

Choosing a calculator to evaluate the cardiovascular risk of patients with systemic inflammatory conditions, such as RA, is a controversial topic. It has been suggested that most risk calculators, which were developed based on trials that did not adjust for RA status, underestimate the cardiovascular risk in RA patients (5). The discordance between various risk scores has been described in the literature (5). For example, based on the Systematic Coronary Risk Evaluation (SCORE) equation (47), developed by the European Society of Cardiology, our patient only had a $2 \%$ risk of fatal cardiovascular events in the next 10 years. This result is discordant, for example, to the current ACC/AHA risk score, which put the risk at $>7.5 \%$. Several other risk scores have also included non-traditional risk factors, including RA, in their algorithms: QRISK3 (48), the Expanded Cardiovascular Risk Prediction Score for Rheumatoid Arthritis (ERS-RA) (49), the ACC/AHA guidelines (50), or the ATACC-RA (51). The superiority of these risk scores to predict cardiovascular events in RA patients compared to general calculators is yet to be established (52).

One of the most comprehensive guides for cardiovascular management in RA patients was provided by EULAR, most recently in 2017 (42). According to these recommendations, cardiovascular disease the setting of co-morbid diabetes).

"risk prediction models should be adapted for patients with RA by a 1.5 multiplication factor, if this is not already included in the model". The validity of this approach, however, has been a matter of dispute (53). The guide is mainly in accordance with the management of cardiovascular prevention in the general population, with a few specific recommendations for RA patients, e.g., disease activity needs to be optimally controlled, lipid profile should "ideally be measured when disease activity is stable or in remission", corticosteroid and NSAID use should be kept to a minimum. Further randomized clinical trials are required to increase the evidence base for cardiovascular prevention in RA.

\section{CONCLUSIONS}

Subcutaneous rheumatoid nodules are a fairly common manifestation of RA. Visceral rheumatoid nodules pose diagnostic challenges, especially in patients in which other causes of nodules may be suspected. The presence of rheumatoid nodules may signal an increased cardiovascular risk. Even when using risk calculators validated for RA patients, calculating an accurate risk for a patient such as ours is challenging. We believe that it is reasonable to presume a severe cardiovascular risk in our patient, despite a normal lipid profile, based on these elements: diabetes, smoking, RA, and the presence of nodulosis. Initiating high-dose statin and abatacept may be a useful primary prevention strategy in complex patients with RA that require biologic therapy.

Conflict of interest: none declared Financial support: none declared

\section{REFERENCES}

1. England BR, Thiele GM, Anderson DR, Mikuls TR. Increased cardiovascular risk in rheumatoid arthritis: mechanisms and implications. BMJ (Clinical research ed). 2018;361:k1036.

2. Puttevils D, De Vusser P, Geusens P, Dens J. Increased cardiovascular risk in patients with rheumatoid arthritis: an overview. Acta cardiologica. 2014;69(2):111-8.

3. Lazzerini PE, Capecchi PL, Laghi-Pasini F. Systemic inflammation and arrhythmic risk: lessons from rheumatoid arthritis. European heart journal. 2017;38(22):1717-27.

4. Crowson CS, Matteson EL, Roger VL, Therneau TM, Gabriel SE. Usefulness of risk scores to estimate the risk of cardiovascular disease in patients with rheumatoid arthritis. The American journal of cardiology. 2012;110(3):420-4.

5. Kawai VK, Chung CP, Solus JF, Oeser A, Raggi P, Stein CM. The ability of the 2013 American College of Cardiology/American Heart Association cardiovascular risk score to identify rheumatoid arthritis patients with high coronary artery calcification scores. Arthritis \& rheumatology (Hoboken, NJ). 2015;67(2):381-5

6. Smolen JS, Burmester GR, Combe B, Curtis JR, Hall S, Haraoui $B$ et al. Head-to-head comparison of certolizumab pegol versus adalimumab in rheumatoid arthritis: 2-year efficacy and safety results from the randomised EXXELERATE study. Lancet (London, England). 2016; 388(10061):2763-74.

7. Kang EH, Jin Y, Brill G, Lewey J, Patorno E, Desai RJ et al. Comparative Cardiovascular Risk of Abatacept and Tumor Necrosis Factor Inhibitors in Patients With Rheumatoid Arthritis With and Without Diabetes Mellitus: A Multidatabase Cohort Study. Journal of the American Heart Association. 2018;7(3).

8. Turesson C, Jacobsson LT. Epidemiology of extra-articular manifestations in rheumatoid arthritis. Scandinavian journal of rheumatology. 2004;33(2):65-72.

9. Garcia-Patos V. Rheumatoid nodule. Seminars in cutaneous medicine and surgery. 2007;26(2):100-7.

10. Sayah A, English JC, 3rd. Rheumatoid arthritis: a review of the cutaneous manifestations. Journal of the American Academy of Dermatology. 2005;53(2):191-209; quiz 10-2.

11. Kim SK, Park SH, Shin IH, Choe JY. Anti-cyclic citrullinated peptide antibody, smoking, alcohol consumption, and disease duration as risk factors for extraarticular manifestations in Korean patients with rheumatoid arthritis. The Journal of rheumatology. 2008;35(6):995-1001. 
12. Wolf $\mathrm{P}$, Gretler J, Aglas F, Auer-Grumbach $\mathrm{P}$, Rainer $\mathrm{F}$. Anticardiolipin antibodies in rheumatoid arthritis: their relation to rheumatoid nodules and cutaneous vascular manifestations. The British journal of dermatology. 1994;131(1):48-51.

13. Nyhall-Wahlin BM, Turesson C, Jacobsson LT, Nilsson JA, Forslind $\mathrm{K}$, Albertsson $\mathrm{K}$ et al. The presence of rheumatoid nodules at early rheumatoid arthritis diagnosis is a sign of extra-articular disease and predicts radiographic progression of joint destruction over 5 years. Scandinavian journal of rheumatology. 2011;40(2):81-7.

14. Kaushik P, Solomon DH, Greenberg JD, Anderson JT, Reed G, Pala $\mathrm{O}$ et al. Subcutaneous nodules are associated with cardiovascular events in patients with rheumatoid arthritis: results from a large US registry. Clinical rheumatology. 2015; 34(10):1697-704.

15. England BR, Sayles H, Michaud K, Caplan L, Davis LA, Cannon GW et al. Cause-Specific Mortality in Male US Veterans With Rheumatoid Arthritis. Arthritis care \& research. 2016;68(1):36-45.

16. Yousem SA, Colby TV, Carrington CB. Lung biopsy in rheumatoid arthritis. The American review of respiratory disease. 1985;131(5):770-7.

17. Walker WC, Wright V. Pulmonary lesions and rheumatoid arthritis. Medicine. 1968;47(6):501-20.

18. Cronstein BN, Eberle MA, Gruber HE, Levin RI. Methotrexate inhibits neutrophil function by stimulating adenosine release from connective tissue cells. Proceedings of the National Academy of Sciences of the United States of America. 1991;88(6):2441-5.

19. Patatanian $\mathrm{E}$, Thompson DF. A review of methotrexate-induced accelerated nodulosis. Pharmacotherapy. 2002;22(9):1157-62.

20. Ahmed SS, Arnett FC, Smith CA, Ahn C, Reveille JD. The HLA-DRB $1{ }^{*} 0401$ allele and the development of methotrexateinduced accelerated rheumatoid nodulosis: a follow-up study of 79 Caucasian patients with rheumatoid arthritis. Medicine. 2001;80(4):271-8.

21. Merrill JT, Shen C, Schreibman D, Coffey D, Zakharenko O, Fisher $\mathrm{R}$ et al. Adenosine $\mathrm{A} 1$ receptor promotion of multinucleated giant cell formation by human monocytes: a mechanism for methotrexate-induced nodulosis in rheumatoid arthritis. Arthritis and rheumatism. 1997;40(7):1308-15.

22. De Stefano R, Frati E, Nargi F, Menza L. Efficacy of rituximab on pulmonary nodulosis occurring or increasing in patients with rheumatoid arthritis during anti-TNF-alpha therapy. Clinical and experimental rheumatology. 2011;29(4):752-3.

23. Andres M, Vela P, Romera C. Marked improvement of lung rheumatoid nodules after treatment with tocilizumab. Rheumatology (Oxford, England). 2012;51(6):1132-4.

24. Tilstra JS, Lienesch DW. Rheumatoid Nodules. Dermatologic clinics. 2015;33(3):361-71.

25. Nyhall-Wahlin BM, Jacobsson LT, Petersson IF, Turesson C. Smoking is a strong risk factor for rheumatoid nodules in early rheumatoid arthritis. Annals of the rheumatic diseases. 2006; 65(5):601-6.

26. Turesson C, Schaid DJ, Weyand CM, Jacobsson LT, Goronzy $\mathrm{JJ}$, Petersson IF et al. Association of HLA-C3 and smoking with vasculitis in patients with rheumatoid arthritis. Arthritis and rheumatism. 2006;54(9):2776-83.

27. Nyhall-Wahlin BM, Petersson IF, Nilsson JA, Jacobsson LT, Turesson $\mathrm{C}$. High disease activity disability burden and smoking predict severe extra-articular manifestations in early rheumatoid arthritis. Rheumatology (Oxford, England). 2009;48(4):416-20.

28. Chodara AM, Wattiaux A, Bartels CM. Managing Cardiovascular Disease Risk in Rheumatoid Arthritis: Clinical Updates and Three Strategic Approaches. Current rheumatology reports. 2017;19(4):16.

29. Avina-Zubieta JA, Thomas J, Sadatsafavi M, Lehman AJ, Lacaille D. Risk of incident cardiovascular events in patients with rheumatoid arthritis: a meta-analysis of observational studies. Annals of the rheumatic diseases. 2012;71(9):1524-9.

30. Avina-Zubieta JA, Choi HK, Sadatsafavi M, Etminan M, Esdaile JM, Lacaille D. Risk of cardiovascular mortality in patients with rheumatoid arthritis: a meta-analysis of observational studies. Arthritis and rheumatism. 2008;59(12):1690-7.

31. Sandoo A, Chanchlani N, Hodson J, Smith JP, Douglas KM, Kitas $\mathrm{GD}$. Classical cardiovascular disease risk factors associate with vascular function and morphology in rheumatoid arthritis: a six-year prospective study. Arthritis research \& therapy. 2013;15(6):R203.

32. Chung CP, Giles JT, Kronmal RA, Post WS, Gelber AC, Petri M et al. Progression of coronary artery atherosclerosis in rheumatoid arthritis: comparison with participants from the Multi-Ethnic Study of Atherosclerosis. Arthritis research \& therapy. 2013;15(5):R134.

33. Jafri K, Bartels CM, Shin D, Gelfand JM, Ogdie A. Incidence and Management of Cardiovascular Risk Factors in Psoriatic Arthritis and Rheumatoid Arthritis: A Population-Based Study. Arthritis care \& research. 2017;69(1):51-7.

34. Sugiyama D, Nishimura K, Tamaki K, Tsuji G, Nakazawa T, Morinobu A et al. Impact of smoking as a risk factor for developing rheumatoid arthritis: a meta-analysis of observational studies. Annals of the rheumatic diseases. 2010;69(1):70-81.

35. Mantel A, Holmqvist M, Nyberg F, Tornling G, Frisell T, Alfredsson L et al. Risk factors for the rapid increase in risk of acute coronary events in patients with new-onset rheumatoid arthritis: a nested case-control study. Arthritis \& rheumatology (Hoboken, NJ). 2015;67(11):2845-54.

36. Solomon DH, Reed GW, Kremer JM, Curtis JR, Farkouh ME, Harrold LR et al. Disease activity in rheumatoid arthritis and the risk of cardiovascular events. Arthritis \& rheumatology (Hoboken, $\mathrm{NJ}$ ). 2015;67(6):1449-55.

37. Arts EE, Fransen J, den Broeder AA, Popa CD, van Riel PL. The effect of disease duration and disease activity on the risk of cardiovascular disease in rheumatoid arthritis patients. Annals of the rheumatic diseases. 2015;74(6):998-1003.

38. Navarro-Millan I, Yang S, DuVall SL, Chen L, Baddley J, Cannon $\mathrm{GW}$ et al. Association of hyperlipidaemia, inflammation and serological status and coronary heart disease among patients with rheumatoid arthritis: data from the National Veterans Health Administration. Annals of the rheumatic diseases. 2016; 75(2):341-7

39. Zhang J, Chen L, Delzell E, Muntner P, Hillegass WB, Safford MM et al. The association between inflammatory markers, serum lipids and the risk of cardiovascular events in patients with rheumatoid arthritis. Annals of the rheumatic diseases. 2014;73(7):1301-8.

40. Gonzalez-Gay MA, Gonzalez-Juanatey C, Lopez-Diaz MJ, Pineiro A, Garcia-Porrua C, Miranda-Filloy JA et al. HLA-DRB1 and persistent chronic inflammation contribute to cardiovascular events and cardiovascular mortality in patients with rheumatoid arthritis. Arthritis and rheumatism. 2007;57(1):125-32.

41. Myasoedova E, Chandran A, Ilhan B, Major BT, Michet CJ, Matteson EL et al. The role of rheumatoid arthritis (RA) flare and cumulative burden of RA severity in the risk of cardiovascular disease. Annals of the rheumatic diseases. 2016;75(3):560-5.

42. Agca R, Heslinga SC, Rollefstad S, Heslinga M, McInnes IB, Peters MJ et al. EULAR recommendations for cardiovascular disease risk management in patients with rheumatoid arthritis and other forms of inflammatory joint disorders: 2015/2016 update. Annals of the rheumatic diseases. 2017;76(1):17-28.

43. Balanescu AR, Bojinca VC, Bojinca M, Donisan T, Balanescu SM. Cardiovascular effects of methotrexate in immune-mediated inflammatory diseases. Experimental and therapeutic medicine. 2019;17(2):1024-9.

44. Toussirot E. Effects of TNFalpha inhibitors on adiposity and other cardiovascular risk factors: implications for the cardiovascular prognosis in patients with rheumatoid arthritis. Expert opinion on drug safety. 2015;14(4):525-32.

45. Roubille C, Richer V, Starnino T, McCourt C, McFarlane A, Fleming $P$ et al. The effects of tumour necrosis factor inhibitors, methotrexate, non-steroidal anti-inflammatory drugs and corticosteroids on cardiovascular events in rheumatoid arthritis, psoriasis and psoriatic arthritis: a systematic review and metaanalysis. Annals of the rheumatic diseases. 2015;74(3):480-9.

46. Solomon DH, Curtis JR, Saag KG, Lii J, Chen L, Harrold LR et al. Cardiovascular risk in rheumatoid arthritis: comparing TNF-alpha blockade with nonbiologic DMARDs. The American journal of medicine. 2013;126(8):730.e9-.e17.

47. Perk J, De Backer G, Gohlke H, Graham I, Reiner Z, Verschuren M et al. European Guidelines on cardiovascular disease prevention in clinical practice (version 2012). The Fifth Joint Task Force of the European Society of Cardiology and Other Societies on Cardiovascular Disease Prevention in Clinical Practice (constituted 
by representatives of nine societies and by invited experts). European heart journal. 2012;33(13):1635-701.

48. Hippisley-Cox J, Coupland C, Brindle P. Development and validation of $Q R I S K 3$ risk prediction algorithms to estimate future risk of cardiovascular disease: prospective cohort study. BMJ (Clinical research ed). 2017;357:j2099.

49. Solomon DH, Greenberg J, Curtis JR, Liu M, Farkouh ME, Tsao $P$ et al. Derivation and internal validation of an expanded cardiovascular risk prediction score for rheumatoid arthritis: a Consortium of Rheumatology Researchers of North America Registry Study. Arthritis \& rheumatology (Hoboken, NJ). 2015; 67(8):1995-2003.

50. Grundy SM, Stone NJ, Bailey AL, Beam C, Birtcher KK, Blumentha RS et al. 2018 AHA/ACC/AACVPR/AAPA/ABC/ACPM/ADA/AGS/
APhA/ASPC/NLA/PCNA Guideline on the Management of Blood Cholesterol. Circulation. 2018:Cir0000000000000625.

51. Bonek K, Gluszko P. Cardiovascular risk assessment in rheumatoid arthritis - controversies and the new approach. Reumatologia. 2016;54(3):128-35.

52. Crowson CS, Gabriel SE, Semb AG, van Riel P, Karpouzas G, Dessein $\mathrm{PH}$ et al. Rheumatoid arthritis-specific cardiovascular risk scores are not superior to general risk scores: a validation analysis of patients from seven countries. Rheumatology (Oxford, England). 2017;56(7):1102-10.

53. Arts EE, Popa CD, Den Broeder AA, Donders R, Sandoo A, Toms $T$ et al. Prediction of cardiovascular risk in rheumatoid arthritis: performance of original and adapted SCORE algorithms. Annals of the rheumatic diseases. 2016;75(4):674-80. 